\title{
Analysis of surgical management of postpartum hemorrhage: At tertiary centre
}

\author{
Sheela S. $\mathbf{R}^{1}$, Sreeramulu $\mathbf{P N}^{2}$, Nagajyothi $\mathrm{S}^{3, *}$ \\ ${ }^{1,2}$ Professor and HOD, ${ }^{3}$ Senior Resident, ${ }^{1,3}$ Dept. of Obstetrics and Gynaecology, ${ }^{2}$ Dept. of General Surgery, Sri Devaraj Urs \\ Medical College and Research Centre, SDUAHER, Kolar, Karnataka, India
}

*Corresponding Author:

Email: jyothireddy68@gmail.com

Received: $13^{\text {th }}$ April, 2018

Accepted: $25^{\text {th }}$ July, 2018

\begin{abstract}
Postpartum hemorrhage (PPH) is one of the leading cause of maternal morbidity and mortality. Major blood loss of over 1000ml of blood occurs in $1-5 \%$ of deliveries. WHO statistics suggest that $25 \%$ of maternal deaths are due to PPH, accounting for more than 1,00,000 maternal deaths annually. ${ }^{2}$

Internal Iliac Artery Ligation (IIAL) is effective method to control intractable PPH and prevent maternal mortality. In our R.L. Jalappa hospital, a tertiary referral centre, we did a retrospective study of patients who are managed for PPH between Jan 2006Jan 2016. In our study, out of 110 PPH patients eighty of them underwent IIAL during the study period.

Out of 80 IIAL cases, PPH due to uterine atony (55\%), uterine rupture (23\%), placenta previa (8\%), placental abruption (6\%), placenta increta (4\%) and broad ligament hematoma (4\%). Medical management was successful in 30 cases. Hysterectomy was done in 6 cases. IIAL was proved to be successful method of controlling hemorrhage in our study. We found that this is one of the best surgical method of management of $\mathrm{PPH}$, so as to retain uterus thereby future fertility.
\end{abstract}

Keywords: Postpartum hemorrhage (PPH), Internal iliac artery ligation (IIAL).

\section{Introduction}

Postpartum hemorrhage is defined as blood loss of more than $500 \mathrm{ml}$ following vaginal delivery or more than $1000 \mathrm{ml}$ following cesarean section. ${ }^{3,4}$

PPH is major cause of maternal mortality world wide ranging from $13 \%$ in developed countries to $34 \%$ in developing countries. ${ }^{5}$ Globally about $11 \%$ of women have severe PPH. In the developing countries like India, PPH affects $9.2 \%$ of all deliveries. ${ }^{6}$ Uterine atony is the commonest cause of PPH that accounts for $80 \%$ of cases. $^{7}$ Other causes of PPH are retained placenta, uterine rupture and lower genital tract laceration etc. Risk factors of atonic PPH includes h/o retained placenta, abruptio placenta, placenta previa, multiple pregnancies, augmentation of labor, prolonged labor, instrumental delivery.

All atonic PPH should be managed initially by intensive medical management. The surgical strategies are considered if medical treatment fails to control bleeding.

The choice of surgical management depends on parity and her desire to conserve uterus. The blood supply of uterus is chiefly derived from internal iliac artery through uterine artery.

IIAL is one of the conservative surgical procedure. Other procedures like uterine artery embolization, uterine artery ligation, B Lynch sutures.

Even after these conservative procedures if there is no arrest of hemorrhage hysterectomy is performed as life saving procedure.

IIAL controls intractable PPH and it reduces pulse pressure by $85 \%$ and pelvic blood flow by $48 \%$ in arteries distal to ligation. ${ }^{8}$
We analysed the documents of our patients who underwent IIAL, to know the effect of IIAL in PPH.

\section{Objective of the Study}

1. To study the management of PPH cases

2. To study the outcome of surgical management of PPH cases

\section{Materials and Methods}

The study was carried out in R.L. Jalappa Hospital and Research Centre, as a retrospective observational study from Jan 2006- Jan 2016. The data was collected from department of OBG. All these patients were between age group of 20-35years. Women with atonic PPH were initially treated with uterine massage, uterotonics and carboprost injection with recommended dosage and at appropriate intervals and also with blood and blood products transfusion.

Following failure of medical treatment, we attempted conservative surgical procedure. Totally 80 patients undergone IILA. Out of which, 15 patients treated with B-lynch sutures, eight patients with uterine artery ligation prior to IIAL and six patients underwent hysterectomy.

In our study, most of the operative procedures were performed on emergency basis.

The surgical technique that we followed was by peritoneum over the iliac vessels was lifted to considerable gap from underlying structures and was opened to enter the retroperitoneal space. The following retroperitoneal structures were identified:

1. Common Iliac artery till its bifurcation

2. External iliac artery, internal iliac artery and Internal iliac vein 
3. Ureter identified and pushed laterally

4. Internal iliac artery was dissected away from internal iliac vein, a double ligature was placed 1 $\mathrm{cm}$ apart and $2-3 \mathrm{~cm}$ away from its origin.

Strict hemostasis was secured. Femoral and Dorsalis pedis arterial pulsations were palpated to rule out inadvertent ligation of external iliac artery (To prevent the error in identifying and ligating internal iliac artery which is mandatory to prevent serious complications of ligation of external iliac artery).

\section{Results}

Over a period of 10 years from Jan 2006 to Jan 2016, 110 cases of PPH data was collected from our R.L. Jalappa Hospital records, Kolar, India. Out of 110 PPH cases 30 patients were managed medically and 80 patients surgically. In our study most of the women belongs to the age group of 26-30 years (45\%) (Table 1). Majority of them were unbooked $(71 \%)$ with us. Booked cases were $21 \%$. We observed PPH was more common in multigravida. 33 cases $(41 \%)$ of Gravida 2, Gravida 3 or $>$ in 25 cases $(31 \%)$ compared to primigravida in 22 cases (28\%) (Table 1).

Most of them were term pregnancies $(72 \%)$ (Table 2). 80 women underwent IIAL for PPH after vaginal delivery (38 cases) or cesarean delivery (42 cases) in our hospital or in other referring centres (Table 2)

Out of 110 PPH cases risk factors associated with PPH are listed in Table 6. Most common risk factors in our study are previous LSCS (23\%), uterine rupture (16.3\%) and anemia (11\%). Out of 23 cases of genital tract injuries, 18 cases were uterine rupture and 5 cases were vaginal lacerations and cervical tears due to prolonged labor and instrumental delivery.
On admission all $110 \mathrm{PPH}$ cases were graded according to Advanced Trauma Life Support (ATLS) classification of shock and were treated accordingly with blood and blood products and other resuscitative measures. Class I and III were more than those in class II and III. Massive transfusion was done in class III and class IV patients Table 4 shows out of 110 PPH cases, 30 were managed medically with uterotonics and carboprost. 80 patients underwent IIAL, among them compression sutures in 15 cases and uterine artery ligation in 8 patients was done prior to IIAL. Due to intractable bleeding 6 patients underwent subtotal hysterectomy. The decision of IIAL was most commonly indicated in uterine atony $(55 \%)$ and uterine rupture $(23 \%)$ Table 5. Majority of them are referred cases in view of PPH following vaginal and caesarean delivery. IIAL was performed at the time of caesarean in 17 cases, laparotomy after vaginal delivery in 38 cases and relaparotomy after caesarean section in 25 cases (Table 5). Six cases underwent hysterectomy due to uterine atony in 2 cases, 3 cases of uterine rupture and in 1 case of placenta increta giving a uterine salvage rate of $90.5 \%$. The maternal complications are outlined in Table 6. All the patients were anemic, $(100 \%)$ requiring transfusion of blood and blood products. Puerperal sepsis seen in 8 cases $(7.2 \%)$ and were combated with appropriate antibiotics and suitable precautions. Table 6 shows perinatal outcome, 15 still births and 65 live births including preterm and term.

In our study, all the patients were monitored in Intensive care unit. None of the women had delayed hemorrhage requiring relaparotomy. IIAL was successful in controlling hemorrahage.

Table 1: Parity wise distribution

\begin{tabular}{|l|c|c|}
\hline \multicolumn{1}{|c|}{ Parity } & Number of Patients & Percentage\% \\
\hline Primigravida & 22 & 28 \\
\hline Gravida 2 & 33 & 41 \\
\hline Gravida 3 or $>$ & 25 & 31 \\
\hline
\end{tabular}

Table 2: Distribution of patients in study according to ATLS classification of shock and its correction.

\begin{tabular}{|l|c|c|c|}
\hline Class & $\begin{array}{c}\text { No. of } \\
\text { patients(n=110) }\end{array}$ & $\begin{array}{c}\text { Percentage } \\
(\boldsymbol{\%})\end{array}$ & Fluid replacement \\
\hline I & 30 & 27.1 & Crystalloids + 2-4 PRBC \\
\hline II & 25 & 23 & Crystalloids + 2-6 PRBC \\
\hline III & 39 & 35.4 & Crystalloids + 10-15 PRBC + 5-10 FFP \\
\hline IV & 16 & 14.5 & Crystalloids + >20 PRBC + >10 FFP + PLTS \\
\hline
\end{tabular}

Table 3: Management in our study

\begin{tabular}{|l|c|c|}
\hline \multicolumn{1}{|c|}{ Treatment } & No. of patients & Percentage (\%) \\
\hline Medical management only & 30 & 27 \\
\hline $\begin{array}{l}\text { Surgical management } \\
\text { iliac artery ligation }\end{array}$ & 80 & 73 \\
\hline Obstetric hysterectomy & 6 & 5.4 \\
\hline
\end{tabular}

\#Out of 80 patients, along with IIAL, Uterine artery ligation in 8 patients and 15 compression sutures were done. 
Table 4: Indications for IIAL

\begin{tabular}{|l|c|c|}
\hline \multicolumn{1}{|c|}{ Indication } & Number of patients & Percentage\% \\
\hline Uterine atony & 43 & 55 \\
\hline Placenta previa & 06 & 8 \\
\hline Abruption placenta & 04 & 6 \\
\hline Placenta increta & 02 & 4 \\
\hline Broad ligament hematoma & 02 & 4 \\
\hline Uterine rupture & 18 & 23 \\
\hline
\end{tabular}

Table 5: Hysterectomy in women who underwent IIAL

\begin{tabular}{|l|c|c|c|}
\hline \multicolumn{1}{|c|}{ Indication } & Total no. of patients & Hysterectomy carried out $-\mathbf{n}(\%)$ & Uterine salvage rate (\%) \\
\hline Uterine atony & 43 & $2(5)$ & 95.3 \\
\hline Uterine rupture & 18 & $3(17)$ & 83 \\
\hline Placenta increta & 02 & $1(50)$ & 50 \\
\hline Total & 63 & $6(9.5)$ & 90.5 \\
\hline
\end{tabular}

Table 6: Maternal outcome

\begin{tabular}{|l|c|c|}
\hline \multicolumn{1}{|c|}{ Maternal complication } & Number of patients(n) & Percentage (\%) \\
\hline Anemia & 110 & 100 \\
\hline Puerperal sepsis & 08 & 7.2 \\
\hline Disseminated intravascular & & \\
Coagulation(DIC) & 06 & 5.4 \\
\hline Acute renal failure & 02 & 1.8 \\
\hline Maternal mortality & 02 & 1.8 \\
\hline
\end{tabular}

\section{Discussion}

In our study the efficacy of bilateral IIAL performed in indicated patients with intractable PPH. There were no procedure related major complications like injury to other major vessels, uterine injury or advertent ligation of external iliac artery.

PPH can cause maternal mortality despite of inadvertent medical treatment and availability of blood products. Probably one of the reasons could be the delay in resorting to surgical techniques once the conservative treatments have failed.

Selective arterial embolization can be done in haemodynamically stable patients. But it requires availability of skilled interventinonal radiologists. Complications do exist like post procedure fever, uterine and bladder necrosis, ischaemic nerve injury, vascular perforation, infection have been reported.

Uterine artery ligation is also very useful technique in PPH management, as occlusion of uterine artery reduces $90 \%$ of blood flow. But in uterine trauma, when avulsed uterine retracts into broad ligament forming hematoma. It is difficult to uterine artery ligation, salvage of uterus.

B-Lynch Brace sutures has been reported in several case series to be successful in controlling refractory uterine bleeding. In this procedure, delayed ischaemic necrosis was reported and also is not useful in central previa. ${ }^{6,9}$

IIAL is one of the effective way of controlling intractable bleeding and also helpful in preserving the uterus
Following bilateral internal iliac artery ligation, uterine arterial pressure drops with virtual elimination of the triple- hammer effect. The average decrease in the pressure being, $77 \%$ with the same side, $14 \%$ with opposite side and $85 \%$ with both sides ligation..$^{9,10}$ Studies reported success rate of IIAL varying from 40 $100 \%,{ }^{11}$ and the procedure averts (prevents) hysterectomy in only $50 \%$ of cases. ${ }^{12}$ Failure rate was more evident in atonic PPH than in other causes of PPH. ${ }^{13}$

In other recent studies, Y. M. Kabadi et al. reported effectiveness of IIAL AS $86.7 \%$. Similarly, a study including 58 patients, Unal et al. reported $87.9 \%$ success rate. With the support of within the frame of literature review, and results of our study, we think that IIAL is life saving method in intractable haemorrhage. In our study success rate is $92.5 \%$.

\section{Conclusion}

In stable patients uterine artery embolisation is advisable with experienced interventional radiologist.

Internal Iliac artery ligation is safe and effective surgical approach to control PPH. We found that this is one of the best treatment modality. We encourage internal iliac artery ligation to retain uterus thereby future fertility.

\section{References}

1. John R Smith, MD; Chief Editor: Ronald M Ramus, MD, et al. Postpartum Hemorrhage.

http://emedicine.medscape.com/article/275038overview\#a6 
2. A. E. Olowokere, O. A. Adekeye, A. Ogunfowokan, O. E. Olagunju and O. O. Irinoye. The prevalence, management and outcome of primary postpartum haemorrhage in selected health care facilities in Nigeria. Int J Nurs. Midwifery; 2013:5(3):28-34.

3. Ravishankar R. B, Praveen P. V, Shruti Hiremath, Keerthana D. S. Anesthetic management of atonic postpartum hemorrhage with hemorrhagic shock and impending cardiac arrest for emergency peripartum hysterectomy; JEBMH. 2015;2:4484-86.

4. Sentilhes L, Vayssière C, Deneux Tharaux C, et al. Postpartum hemorrhage: guidelines for clinical practice from the French College of Gynaecologists and Obstetricians (CNGOF): in collaboration with the French Society of Anesthesiology and Intensive Care (SFAR). Eur J Obstet Gynecol Reprod Biol. 2016;198:12-21.

5. Lale Say, Doris Chou, Alison Gemmill, Özge Tunçalp, AnnBeth Moller, Jane Daniels, A Metin Gülmezoglu. Global causes of maternal death: a WHO systematic analysis. Lancet Glob Health. 2014;2:e323-33.

6. Mousa HA, Blum J, Abou El, Senoun G, Shakur H, Alfirevic Z. Treatment for primary postpartum hemorrhage. Cochrane Database of Systematic Reviews 2014, Issue 2. Art. No.: CD003249. DOI: 10.1002/14651858.CD003249. pub3.

7. VM. Joshi, SR otiv, R Majumder, YA Nikam, M Shrivastava. Internal iliac artery ligation for arresting postpartum hemorrhage; BJOG.2007

8. Cengiz, Hüseyin, et al. "Management of intractable postpartum haemorrhage in a tertiary center: A 5-year experience." Nigerian medical journal: journal of the Nigeria Medical Association 53.2 (2012): 85.9. Ammbalal Gurram. Bilateral internal iliac artery ligation in postpartum haemorrhage Med Pulse - International Medical Journal. 2016;3(7): 613 .
9. Y. M. Kabadi, Harsha B. Emergency internal iliac artery ligation: a conservative lifesaving procedure. Int J Reprod Contracept Obstet Gynecol. 2015;4(5):1364-1366.

10. Pooja Tandon, Sunil Kumar Juneja, and Bishav Mohan. Angiographic embolization for intractable obstetrical bleeding. Int J Appl Basic Med Res. 2014;4(1):25-27.

11. Gadappa, S., Deshpande, S., Yelikar, K. and Gadekar, S. Role of Anterior Division of Internal Iliac Artery Ligation in Refractory Postpartum Haemorrhage-A Tertiary Care Hospital Based Study. Open Journal of Obstetrics and Gynecology. 2016;6:725-733.

12. Kayem, Gilles MD, PhD; Kurinczuk, Jennifer J. MSc, MD; Alfirevic, Zarko MD; Spark. Uterine Compression Sutures for the Management of Severe Postpartum Hemorrhage. Obstetrics \& Gynecology. 2011;117(1):14-20.

13. Unal O, Kars B, Buyukbayrak EE, Karsidag AY, Turan C. The effectiveness of bilateral hypogastric artery ligation for obstetric hemorrhage in three different underlying conditions and its impact on future fertility. J Matern Fetal Neonatal Med. 2011;24(10):1273-6.

14. Kabadi Y M, Harsha B. Emergency internal iliac artery ligation: a conservative lifesaving procedure. Int J Reprod Contracept Obstet Gynecol. 2015 Oct;4(5):1364-1366.

15. Chelli D, Boudaya F, Dimassi K, Gharbi B, Najjar I et al. Hypogastric artery ligation for post-partum hemorrhage. $J$ Gyneco Obstet Biol Reprod (Paris). 2010;39(1):43-9.

How to cite this article: Sheela S. R,
Sreeramulu PN, Nagajyothi S. Analysis of
surgical management of postpartum
hemorrhage: At tertiary centre. Ind J Obstet
Gynecol Res. 2018;5(3):377-380.

